\title{
Analysis of Optical Properties and Structures of Nitrogen Doped Gallium Oxide*
}

\author{
Yuma Kato ${ }^{\dagger}$ \\ Applied Chemistry and Bioengineering, Graduate School of Engineering, Osaka City University, \\ 3-3-138 Sugimoto, Sumiyoshi-ku, Osaka 558-8585, Japan
}

Muneaki Yamamoto

Materials, Physics and Energy Engineering, Graduate School of Engineering, Nagoya University, Furo-cho, Chikusa-ku, Nagoya 464-8603, Japan

\author{
Akiyo Ozawa \\ Applied Chemistry and Bioengineering, Graduate School of Engineering, Osaka City University, \\ 3-3-138 Sugimoto, Sumiyoshi-ku, Osaka 558-8585, Japan and \\ Corporate Research Laboratories, Research $\&$ Development Division, Sakai Chemical Industry, Co., Ltd., \\ 5-2, Ebisujima-cho, Sakai-ku, Sakai 590-0815, Japan \\ Yu Kawaguchi \\ Applied Chemistry and Bioengineering, Graduate School of Engineering, Osaka City University, \\ 3-3-138 Sugimoto, Sumiyoshi-ku, Osaka 558-8585, Japan
Akinobu Miyoshi, Takayoshi Oshima, and Kazuhiko Maeda
Department of Chemistry, Graduate School of Science and Engineering, Tokyo Institute of Technology, 2-12-1-NE-2 Ookayama, Meguro-ku, Tokyo 152-8550, Japan \\ Tomoko Yoshida \\ Advanced Research Institute for Natural Science and Technology, Osaka City University, \\ 3-3-138 Sugimoto, Sumiyoshi-ku, Osaka 558-8585, Japan \\ (Received 12 January 2018; Accepted 5 May 2018; Published 14 June 2018)
}

\begin{abstract}
To promote photocatalytic activity of gallium oxides $\left(\mathrm{Ga}_{2} \mathrm{O}_{3}\right)$ on $\mathrm{CO}_{2}$ reduction with water under visible light irradiation, we have tried nitrogen doping into $\mathrm{Ga}_{2} \mathrm{O}_{3}$ with different crystalline structures. In diffuse reflectance UV-vis spectra, absorption bands appeared in the visible light region after the nitrogen doping and the absorption edge shifted to a longer wavelength region with increasing nitrogen doping temperature. N K-edge XANES analysis clearly showed two kinds of nitrogen species doped in the samples; gallium nitride (GaN) species and molecular like nitrogen. In XRD patterns, nitrogen doping at temperatures above $823 \mathrm{~K}$, gallium nitride phases appeared while the original crystal structures of gallium oxide samples maintained when nitrogen doping temperature was less than $823 \mathrm{~K}$. However, photocatalytic $\mathrm{CO}_{2}$ reduction under visible light irradiation was insignificant for all the nitrogen doped samples, because nitrogen doped in $\mathrm{Ga}_{2} \mathrm{O}_{3}$ samples was unstable in water under the visible light irradiation. [DOI: 10.1380/ejssnt.2018.262]
\end{abstract}

Keywords: Gallium oxide; Nitriding; Visible light response; XAFS

\section{INTRODUCTION}

Photocatalytic $\mathrm{CO}_{2}$ reduction with water has attracted much attention because of its potential to realize an artificial photosynthesis [1-3]. To use water as a reductant for $\mathrm{CO}_{2}$ reduction, the activation of water is intrinsically required. Therefore, heterogeneous metal oxide photocatalysts which can activate water have been widely studied targeting $\mathrm{CO}_{2}$ reduction with water [4-11]. Recently, Akatsuka et al. and Teramura et al. have found that gallium oxide $\left(\mathrm{Ga}_{2} \mathrm{O}_{3}\right)$ shows photocatalytic activity for the $\mathrm{CO}_{2}$ reduction with water producing $\mathrm{CO}$ under ultra violet (UV) light irradiation [5, 6, 12-14]. However, the

\footnotetext{
* This paper was presented at the 11th International Symposium on Atomic Level Characterizations for New Materials and Devices '17, Aqua Kauai Beach Resort, Kauai, Hawaii, USA, December $3-8,2017$.

† Corresponding author: m17tc011@eb.osaka-cu.ac.jp
}

reduction was not observed under visible light irradiation because the band gap of $\mathrm{Ga}_{2} \mathrm{O}_{3}$ is too wide to absorb the visible light.

It is well known that only $6 \%$ or less energy of sunlight is given by UV light, while more than $50 \%$ by visible light [15]. For the efficient use of the sunlight energy, it is important to prepare photocatalysts driven by the visible light. Recently, it has been reported that nitrogen doping into metal oxides contributes to narrowing of their band gap, providing a visible-light response because $\mathrm{N} \mathrm{2p}$ orbitals are newly formed above $\mathrm{O} 2 \mathrm{p}$ orbitals in their valence band $[16,17]$. To generate visible light response in $\mathrm{Ga}_{2} \mathrm{O}_{3}$ photocatalysts, we have tried nitrogen doping into $\mathrm{Ga}_{2} \mathrm{O}_{3}$ samples having different crystal structures. The results of the nitrogen doping, i.e., structural changes and the amount and chemical state of doped nitrogen were investigated by various analyzing techniques. Photocatalytic activity of the nitrogen doped samples for the $\mathrm{CO}_{2}$ reduction with water under visible light irradiation was examined. 

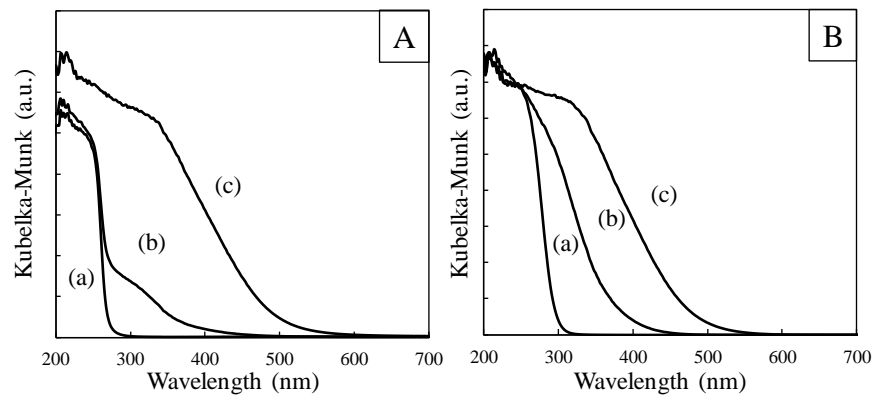

FIG. 1. DR UV-vis spectra of CA- $\mathrm{Ga}_{2} \mathrm{O}_{3}$ and $873-\mathrm{Ga}_{2} \mathrm{O}_{3}$ samples before and after nitrogen doping. A: (a) $\mathrm{CA}-\mathrm{Ga}_{2} \mathrm{O}_{3}$, (b) $\mathrm{CA}-\mathrm{Ga}_{2} \mathrm{O}_{3}-823$, (c) $\mathrm{CA}-\mathrm{Ga}_{2} \mathrm{O}_{3}-973$, B: (a) $873-\mathrm{Ga}_{2} \mathrm{O}_{3}$, (b) $873-\mathrm{Ga}_{2} \mathrm{O}_{3}-823$, (c) $873-\mathrm{Ga}_{2} \mathrm{O}_{3}-873$.

\section{EXPERIMENTAL}

\section{A. Sample preparation}

It has been reported that $\mathrm{Ga}_{2} \mathrm{O}_{3}$ prepared by calcination of gallium nitrate at around $800 \mathrm{~K}$ showed high photocatalytic activity for $\mathrm{CO}_{2}$ reduction with water under UV light irradiation [18]. In this study, $\mathrm{Ga}_{2} \mathrm{O}_{3}$ samples were prepared by calcination of $\mathrm{Ga}\left(\mathrm{NO}_{3}\right)_{3} \cdot 8 \mathrm{H}_{2} \mathrm{O}$ (Kishida Chemical, $99.0 \%$ ) in air at $873 \mathrm{~K}$ for $4 \mathrm{~h}$. Thus obtained samples are referred to as $873-\mathrm{Ga}_{2} \mathrm{O}_{3}$. Nitrogen doping was performed for $873-\mathrm{Ga}_{2} \mathrm{O}_{3}$ and commercially available $\mathrm{Ga}_{2} \mathrm{O}_{3}$ (High Purity Chemicals, 99.99\%, CA-Ga $\mathrm{O}_{3}$ ) under continuous flow of $\mathrm{NH}_{3}$ gas $\left(50 \mathrm{~mL} \mathrm{~min}{ }^{-1}\right)$. Nitrogen doping temperature and time for $873-\mathrm{Ga}_{2} \mathrm{O}_{3}$ were $823 \mathrm{~K}$ or $873 \mathrm{~K}$ for $5 \mathrm{~h}$, and those for $\mathrm{CA}-\mathrm{Ga}_{2} \mathrm{O}_{3}$ were $823 \mathrm{~K}$ for $5 \mathrm{~h}$ or $973 \mathrm{~K}$ for $10 \mathrm{~h}$. These samples are referred to as $873-\mathrm{Ga}_{2} \mathrm{O}_{3}-\mathrm{Y}$ and $\mathrm{CA}-\mathrm{Ga}_{2} \mathrm{O}_{3}-\mathrm{Y}$ (Y: nitrogen doping temperature), respectively.

\section{B. Characterization}

The crystalline structures of the nitrogen doped samples were investigated by X-ray diffraction (XRD) analysis. XRD patterns of the samples were recorded on a MiniFlex600 (Rigaku) using $\mathrm{Cu} \mathrm{K} \alpha$ as the radiation source with an operating voltage of $40 \mathrm{kV}$ and current of $15 \mathrm{~mA}$. The XRD patterns were collected at $2 \theta$ angles of $20-60^{\circ}$. The $2 \theta$ step size was $0.02^{\circ}$, and the scanning rate was 10 degree/min.

Diffuse reflectance (DR) UV-visible spectra were measured using UV-visible spectrophotometer (JASCO, V$670)$. The spectra of $\mathrm{BaSO}_{4}$ powder was used as the reference.

N K-edge and Ga K-edge XAFS measurements were carried out at BL7U and BL5S1 of Aichi Synchrotron Radiation Center, respectively. N K-edge XAFS spectra were measured in a total electron yield mode and $\mathrm{Ga}$ $\mathrm{K}$-edge XAFS spectra in a transmission mode.

\section{Photocatalytic $\mathrm{CO}_{2}$ reduction}

Photocatalytic $\mathrm{CO}_{2}$ reduction with water was carried out using the nitrogen doped samples. Before the reac-

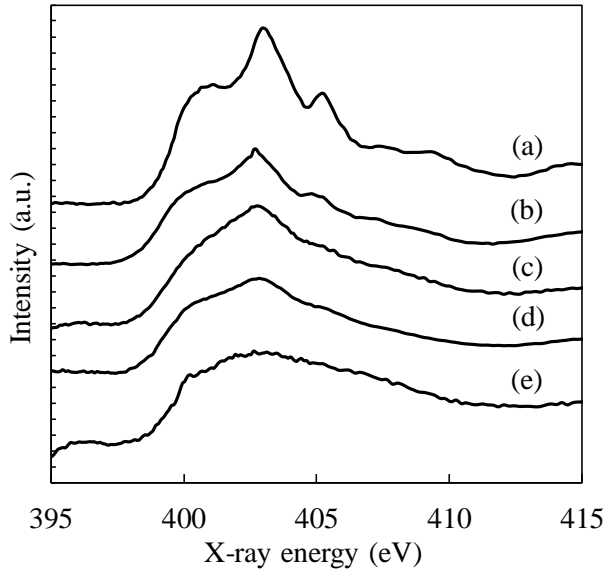

FIG. 2. N K-edge XANES spectra of (a) GaN (ref.), (b) $\mathrm{CA}-\mathrm{Ga}_{2} \mathrm{O}_{3}-973$, (c) $\mathrm{CA}-\mathrm{Ga}_{2} \mathrm{O}_{3}-823$, (d) $873-\mathrm{Ga}_{2} \mathrm{O}_{3}-873$, (e) $873-\mathrm{Ga}_{2} \mathrm{O}_{3}-823$.

tion, the sample $(0.1 \mathrm{~g})$ was exposed to visible-light generated by a $300 \mathrm{~W}$ Xe lamp with a cut filter for $\lambda>420 \mathrm{~nm}$ for $1 \mathrm{~h}$ under $\mathrm{CO}_{2}$ gas with a flow rate of $3 \mathrm{~mL} / \mathrm{min}$, where the light intensity measured in the range of $415 \pm 55 \mathrm{~nm}$ was $127 \mathrm{~mW} / \mathrm{cm}^{2}$. Then a $\mathrm{NaHCO}_{3}$ aqueous solution $\left(\mathrm{H}_{2} \mathrm{O} 10 \mathrm{~mL}, \mathrm{NaHCO}_{3} 0.92 \mathrm{~g}\right)$ was added to the reactor cell in dark. After $1 \mathrm{~h}$, the background in dark was measured with an online gas chromatograph equipped with a thermal conductivity detector (GC-TCD, Shimadzu GC$8 \mathrm{APT}$ ). Subsequently, photocatalytic reduction of $\mathrm{CO}_{2}$ under the visible-light irradiation was started and $\mathrm{CO}$, $\mathrm{H}_{2}$, and $\mathrm{O}_{2}$ production rates were measured for $5 \mathrm{~h}$.

\section{RESULTS AND DISCUSSION}

\section{A. Optical properties of nitrogen doped samples}

Fig. 1 shows DR UV-vis spectra of $\mathrm{CA}-\mathrm{Ga}_{2} \mathrm{O}_{3}-\mathrm{Y}$ and $873-\mathrm{Ga}_{2} \mathrm{O}_{3}-\mathrm{Y}$ samples. Intensity of these spectra was converted to the Kubelka-Munk function. The DR spectra indicate that absorption bands appeared in the visible light region after the nitrogen doping. The absorption edge shifted to a longer wavelength region with increasing the temperature of nitrogen doping, suggesting the enhancement of the nitrogen doping at higher temperatures. It is noticeable that the absorption band in the visible light region was much smaller for $\mathrm{CA}-\mathrm{Ga}_{2} \mathrm{O}_{3}-823$ compared with $873-\mathrm{Ga}_{2} \mathrm{O}_{3}-823$, though both samples were nitrogen-doped at the same temperature. In the spectrum of $873-\mathrm{Ga}_{2} \mathrm{O}_{3}-873$, the band shifted to $550 \mathrm{~nm}$ in a similar way to $\mathrm{CA}-\mathrm{Ga}_{2} \mathrm{O}_{3}-973$. These results suggest that the $873-\mathrm{Ga}_{2} \mathrm{O}_{3}$ includes larger amount of doped nitrogen than that for $\mathrm{CA}-\mathrm{Ga}_{2} \mathrm{O}_{3}$.

\section{B. Chemical states of doped nitrogen}

N K-edge XANES spectra of the nitrogen doped samples shown in Fig. 2 confirm that the all samples contain nitrogen as the appearance of clear absorptions originated from $\sigma$ and $\pi$ bonds of nitrogen species [19, 20]. The chemical sifts or peak broadening of the XANES spectra 

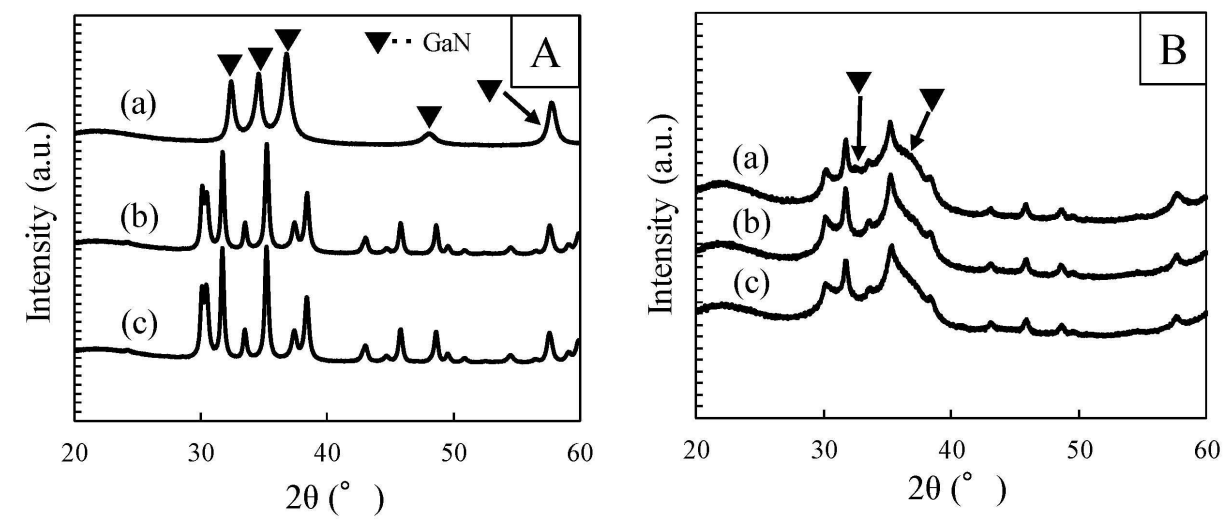

FIG. 3. X-ray diffraction patters of CA- $\mathrm{Ga}_{2} \mathrm{O}_{3}$ and $873-\mathrm{Ga}_{2} \mathrm{O}_{3}$ samples before and after nitrogen doping. A: (a) CA-Ga $2 \mathrm{O}_{3}-973$, (b) $\mathrm{CA}-\mathrm{Ga}_{2} \mathrm{O}_{3}-823$, (c) $\mathrm{CA}-\mathrm{Ga}_{2} \mathrm{O}_{3}, \mathrm{~B}$ : (a) $873-\mathrm{Ga}_{2} \mathrm{O}_{3}-873$ (b) $873-\mathrm{Ga}_{2} \mathrm{O}_{3}-823$ (c) $873-\mathrm{Ga}_{2} \mathrm{O}_{3}$.
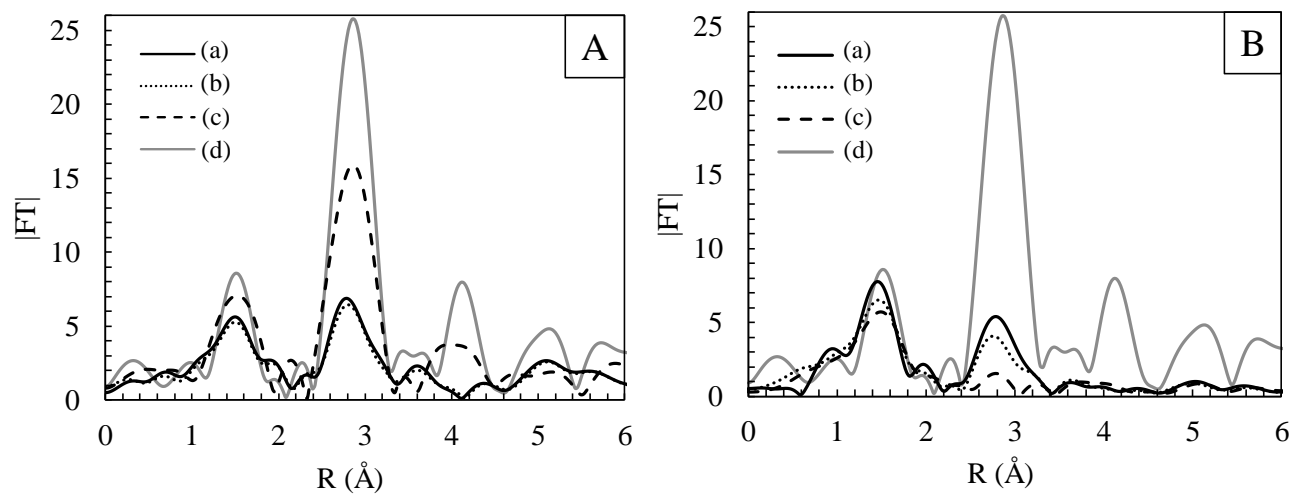

FIG. 4. Radial structure functions for Ga K-edge EXAFS spectra of CA- $\mathrm{Ga}_{2} \mathrm{O}_{3}$ and $873-\mathrm{Ga}_{2} \mathrm{O}_{3}$ samples before and after the nitrogen doping. A: (a) $\mathrm{CA}-\mathrm{Ga}_{2} \mathrm{O}_{3}$, (b) $\mathrm{CA}-\mathrm{Ga}_{2} \mathrm{O}_{3}-823$, (c) $\mathrm{CA}-\mathrm{Ga}_{2} \mathrm{O}_{3}-973$, (d) $\mathrm{GaN}$ reference, B: (a) 873-Ga $\mathrm{O}_{3}$, (b) $873-\mathrm{Ga}_{2} \mathrm{O}_{3}-823$, (c) $873-\mathrm{Ga}_{2} \mathrm{O}_{3}-873$, (d) GaN reference.

and the redshift of absorption edge in DR UV-vis spectra reflect chemical nature of the doped nitrogen as discussed below.

The XANES features of the CA- $\mathrm{Ga}_{2} \mathrm{O}_{3}-973$, CA$\mathrm{Ga}_{2} \mathrm{O}_{3}-823$ and $873-\mathrm{Ga}_{2} \mathrm{O}_{3}-873$ [Fig. 2(b-d)] were similar to that of a $\mathrm{GaN}$ reference sample [Fig. 2(a)]. On the other hand, the XANES spectra of $873-\mathrm{Ga}_{2} \mathrm{O}_{3}-823$, [Fig. 2(e)] exhibited a broad feature having a small peak around $400 \mathrm{eV}$. Metson et al. and Chiou et al. have reported that this peak corresponds to molecular nitrogen $[19,20]$. Therefore, the $400 \mathrm{eV}$ peak could be associated with the presence of interstitial molecular like nitrogen or small bubbles containing $\mathrm{N}_{2}$. Thus, the XANES analysis indicates the existence of at least two different kinds of nitrogen chemical states in the samples; i.e., nitrogen bonded to Ga atom ( $\mathrm{Ga}-\mathrm{N}$ species) and molecular like nitrogen.

\section{Structural analysis of $\mathrm{Ga}_{2} \mathrm{O}_{3}$ samples before and after the nitrogen doping}

Fig. 3 shows X-ray diffraction patters of CA-Ga $\mathrm{Ga}_{3}$ and 873- $\mathrm{Ga}_{2} \mathrm{O}_{3}$ samples before and after the nitrogen doping. The crystalline structure of $\mathrm{CA}-\mathrm{Ga}_{2} \mathrm{O}_{3}$ was assigned to $\beta$-phase $\mathrm{Ga}_{2} \mathrm{O}_{3}$. After the nitrogen doping, the original crystal structure maintained in $\mathrm{CA}-\mathrm{Ga}_{2} \mathrm{O}_{3}-823$, while $\mathrm{GaN}$ phase dominated in $\mathrm{CA}-\mathrm{Ga}_{2} \mathrm{O}_{3}-973$. The XRD pat- tern of $873-\mathrm{Ga}_{2} \mathrm{O}_{3}$ exhibited the broad diffraction peaks of $\gamma$-phase $\mathrm{Ga}_{2} \mathrm{O}_{3}$ together with some weak peaks attributed to $\beta$-phase $\mathrm{Ga}_{2} \mathrm{O}_{3}$, indicating the coexistence of the $\beta$ - and $\gamma$-phases. The XRD pattern of $873-\mathrm{Ga}_{2} \mathrm{O}_{3}-$ 823 was almost the same as that of $873-\mathrm{Ga}_{2} \mathrm{O}_{3}$, whereas small diffraction peaks attributed to $\mathrm{GaN}$ phase were included in 873- $\mathrm{Ga}_{2} \mathrm{O}_{3}-873$. Thus, nitrogen doping at temperatures above $823 \mathrm{~K}$ induced the precipitation of GaN phase, while the original crystal structures fundamentally maintained in $\mathrm{CA}-\mathrm{Ga}_{2} \mathrm{O}_{3}$ and $873-\mathrm{Ga}_{2} \mathrm{O}_{3}$ samples when nitrogen doping temperatures were below $823 \mathrm{~K}$.

The local structures of CA- $\mathrm{Ga}_{2} \mathrm{O}_{3}$ and $873-\mathrm{Ga}_{2} \mathrm{O}_{3}$ samples before and after the nitrogen doping were also investigated by Ga K-edge EXAFS analysis. The Fourier transform was performed on each EXAFS spectrum in the range from $3 \AA^{-1}$ to $12 \AA^{-1}$ and the radial structure function (RSF) was obtained as shown in Fig. 4. Peak appeared at $1-2 \AA$ is assigned to the backscattering from the adjacent oxygen $(\mathrm{O})$ or nitrogen $(\mathrm{N})$ atoms $(\mathrm{Ga}-\mathrm{O}$ or $\mathrm{Ga}-$ $\mathrm{N}$ bond), and peaks around $3 \AA$ show the presence of the second-neighboring gallium atoms $[\mathrm{Ga}-(\mathrm{O}, \mathrm{N})-\mathrm{Ga}$ bond] The backscattering amplitude and phase shift of $\mathrm{O}$ and $\mathrm{N}$ are almost the same. This inhibits the distinction of $\mathrm{Ga}-\mathrm{O}$ and $\mathrm{Ga}-\mathrm{N}$ bonds and makes discussion about the formation of $\mathrm{Ga}-\mathrm{N}$ bonds difficult. However, the changes in local structure were proposed by considering the XRD patterns given results in Fig. 3 .

In the $\mathrm{RSF}$ of $\mathrm{CA}-\mathrm{Ga}_{2} \mathrm{O}_{3}$, the peak around $3 \AA$ at- 
tributed to $\mathrm{Ga}-\mathrm{O}-\mathrm{Ga}$ bond was higher than the peak at 1-2 $\AA$ due to $\mathrm{Ga}-\mathrm{O}$ bond [Fig. $4 \mathrm{~A}(\mathrm{a})$ ], which should be characteristic of the local structure of $\beta$-phase $\mathrm{Ga}_{2} \mathrm{O}_{3}$. Although the RSF of $\mathrm{CA}-\mathrm{Ga}_{2} \mathrm{O}_{3}$ was not changed by the nitrogen doping at $823 \mathrm{~K}$ [Fig. 4A(b)], a large peak around $3 \AA$ newly appeared with the nitrogen doping at $923 \mathrm{~K}$ [Fig. $4 \mathrm{~A}(\mathrm{c})]$. This large peak is attributed to GaN structure $(\mathrm{Ga}-\mathrm{N}-\mathrm{Ga}$ bond), referring the RSF of commercially available GaN.

On the other hand, in $\mathrm{RSF}$ of $873-\mathrm{Ga}_{2} \mathrm{O}_{3}$ in Fig. $4 \mathrm{~B}$ whose crystalline structure was assigned to be mixture of $\gamma$ and $\beta$ phases of $\mathrm{Ga}_{2} \mathrm{O}_{3}$ as revealed from the XRD analysis, the peak at $1-2 \AA$ is much higher than the peak around $3 \AA$. Nitrogen doping into $873-\mathrm{Ga}_{2} \mathrm{O}_{3}$ samples reduced both peaks attributed to $\mathrm{Ga}-\mathrm{O}$ and $\mathrm{Ga}-\mathrm{O}-\mathrm{Ga}$ bonds with more significant reduction in $873-\mathrm{Ga}_{2} \mathrm{O}_{3}-823$ compared with that in $\mathrm{CA}-\mathrm{Ga}_{2} \mathrm{O}_{3}-823$. This result suggests that the original local structure of $873-\mathrm{Ga}_{2} \mathrm{O}_{3}$ changed since larger amount of $\mathrm{Ga}-\mathrm{N}$ bonds were formed at higher nitrogen doping temperature.

As discussed above, XRD measurements suggested that both crystal structures of CA- $\mathrm{Ga}_{2} \mathrm{O}_{3}$ and $873-\mathrm{Ga}_{2} \mathrm{O}_{3}$ samples fundamentally maintained after the nitrogen doping at $823 \mathrm{~K}$. However, the local structure of $873-\mathrm{Ga}_{2} \mathrm{O}_{3}$ already changed by introducing some amount of nitrogen molecules whereas the local structure of $\mathrm{CA}-\mathrm{Ga}_{2} \mathrm{O}_{3}$ showed no remarkable change. Generally, it is well known that $\mathrm{Ga}_{2} \mathrm{O}_{3}$ is a so-called crystal polymorph, which could take five different crystal structures $\left(\alpha-\mathrm{Ga}_{2} \mathrm{O}_{3}, \beta-\mathrm{Ga}_{2} \mathrm{O}_{3}\right.$, $\gamma-\mathrm{Ga}_{2} \mathrm{O}_{3}, \delta-\mathrm{Ga}_{2} \mathrm{O}_{3}$, and $\left.\varepsilon-\mathrm{Ga}_{2} \mathrm{O}_{3}\right)$. Among them, $\gamma$ $\mathrm{Ga}_{2} \mathrm{O}_{3}$ exhibits the defective amorphous-like phase, while $\beta-\mathrm{Ga}_{2} \mathrm{O}_{3}$ is the most stable phase $[21,22]$. Therefore, the amount of doped nitrogen was larger in $873-\mathrm{Ga}_{2} \mathrm{O}_{3}$ rather than that in $\mathrm{CA}-\mathrm{Ga}_{2} \mathrm{O}_{3}$. In $\mathrm{CA}-\mathrm{Ga}_{2} \mathrm{O}_{3}$, nitrogen would be introduced into $\beta-\mathrm{Ga}_{2} \mathrm{O}_{3}$ phase accompanying defects formation. Thus, defective structure such as $\gamma$ $\mathrm{Ga}_{2} \mathrm{O}_{3}$ rather than stable $\beta-\mathrm{Ga}_{2} \mathrm{O}_{3}$ structure allows larger amount of nitrogen doping.

\section{Photocatalytic $\mathrm{CO}_{2}$ reduction with water}

Although photocatalytic $\mathrm{CO}_{2}$ reduction with water under visible light irradiation was conducted using the ni- trogen doped samples $\left(823-\mathrm{Ga}_{2} \mathrm{O}_{3}-\mathrm{Y}\right.$ and $\left.\mathrm{CA}-\mathrm{Ga}_{2} \mathrm{O}_{3}-\mathrm{Y}\right)$, the photocatalytic activity was insignificant. Instead the color of the nitrogen doped samples changed from yellow to white. The color change suggests that the doped nitrogen atoms were oxidized by photogenerated holes and released from the samples $\left(2 \mathrm{~N}^{3-}+6 \mathrm{~h}^{+} \rightarrow \mathrm{N}_{2}\right)$ [23, 24]. In particular, the defective amorphous like $\gamma-\mathrm{Ga}_{2} \mathrm{O}_{3}$ phase might enhance the nitrogen evolution from the samples. Thus, the nitrogen doped $\mathrm{Ga}_{2} \mathrm{O}_{3}$ samples were unstable in water under the visible light irradiation, even if they had initially some activity for $\mathrm{CO}_{2}$ reduction. Now we are trying to suppress the self-oxidation and nitrogen evolution of the samples.

\section{CONCLUSION}

Based on our previous work indicating potential photocatalytic activity of $\mathrm{Ga}_{2} \mathrm{O}_{3}$ for $\mathrm{CO}_{2}$ reduction with water under UV light irradiation, we have tried nitrogen doping into gallium oxide samples having different crystalline structures with using $\mathrm{NH}_{3}$ in order to enhance their photocatalytic activity under visible light. The nitrogen doping was successfully done and optical properties were improved to absorb visible light. However, nitrogen doped into $\mathrm{Ga}_{2} \mathrm{O}_{3}$ samples was unstable in water under the visible light irradiation. Hence, photocatalytic $\mathrm{CO}_{2}$ reduction under visible light irradiation was insignificant. Stabilization of doped nitrogen in $\mathrm{Ga}_{2} \mathrm{O}_{3}$ in water remains an important issue to resolve.

\section{ACKNOWLEDGMENTS}

This study was supported by JSPS KAKENHI Grant Numbers JP16H06440, JP16H06441, and JP16H06438 (Synthesis of Mixed Anion Compounds toward Novel Functionalities).
[1] J. L. G. Fierro, Catal. Lett. 22, 67 (1993)

[2] D. Chen, X. Zhang, and A. F. Lee, J. Mater. Chem. A 3, 14487 (2015).

[3] A. Kubacka, M. Fernandez-Garcia, and G. Colon, Chem. Rev. 112, 1555 (2012).

[4] K. Iizuka, T. Wato, Y. Miseki, K. Saito, and A. Kudo, J. Am. Chem. Soc. 133, 20863 (2011).

[5] M. Akatsuka, T. Yoshida, N. Yamamoto, M. Yamamoto, S. Ogawa, and S. Yagi, J. Phys.: Conf. Ser. 712, 012056 (2016).

[6] K. Teramura, Z. Wang, S. Hosokawa, Y. Sakata, and T. Tanaka, Chem. Eur. J. 20, 9906 (2014).

[7] Z. Wang, K. Teramura, S. Hosokawa, and T. Tanaka, J. Mater. Chem. A 3, 11313 (2015).

[8] T. Takayama, K. Tanabe, K. Saito, A. Iwase, and A. Kudo, Phys. Chem. Chem. Phys. 16, 24417 (2014).
[9] T. Takayama, A. Iwase, and A. Kudo, Bull. Chem. Soc. Jpn. 88, 538 (2015).

[10] Z. Wang, K. Teramura, S. Hosokawa, and T. Tanaka, Appl. Catal. B 163, 241 (2015).

[11] H. Yoshida, L. Zhang, M. Sato, T. Morikawa, T. Kajino, T. Sekito, S. Matsumoto, and H. Hirata, Catal. Today 251, 132 (2015).

[12] N. Yamamoto, T. Yoshida, S. Yagi, Z. Like, T. Mizutani, S. Ogawa, H. Nameki, and H. Yoshida, e-J. Surf. Sci. Nanotech. 12, 263 (2014).

[13] M. Yamamoto, T. Yoshida, N. Yamamoto, T. Nomoto, A. Yamamoto, H. Yoshida, and S. Yagi, J. Phys.: Conf. Ser. 712, 012074 (2016).

[14] M. Yamamoto, T. Yoshida, N. Yamamoto, T. Nomoto, Y. Yamamoto, S. Yagi, and H. Yoshida, J. Mater. Chem. A 3, 16810 (2015). 
[15] A. Nakada, T. Nakashima, K. Sekizawa, K. Maeda, and O. Ishitani, Chem. Sci. 7, 4364 (2016).

[16] R. Asahi, T. Owaki, K. Aoki, and Y. Taga, Science 293, 269 (2001).

[17] R. Asahi and T. Morikawa, Chem. Phys. 339, 57 (2007).

[18] Y. Kawaguchi, M. Akatsuka, M. Yamamoto, K. Yoshioka, A. Ozawa, Y. Kato, and T. Yoshida, J. Photochem. Photobiol. A 358, 459 (2018).

[19] J. B. Metson, H. J. Trodahl, B. J. Ruck, U. D. Lanke, and A. Bittar, Surf. Interface Anal. 35, 719 (2003).
[20] J. W. Chiou, J. C. Jan, H. M. Tsai, and W. F. Ponga, Appl. Phys. Lett. 82, 3949 (2003).

[21] R. Roy, V. G. Hill, and E. F. Osborn, J. Am. Chem. Soc. 74, 719 (1952).

[22] L. Li, W. Wei, and M. Behrens, Solid State Sci. 14, 971 (2012).

[23] G. Hitoki, T. Takata, J. N. Kondo, M. Hara, H. Kobayashi, and K. Domen, Chem. Commun. 1698 (2002).

[24] M. Higashi, K. Domen, and R. Abe, J. Am. Chem. Soc. 134, 6968 (2012). 